\title{
THE INFLUENCE OF FAMILY DYNAMICS ON THE PRODUCTIVITY OF WORKING MOTHERS IN A MOTOR COMPANY IN SOUTH AFRICA
}

\section{Liesl Riekert, Florinda Taute}

\section{INTRODUCTION}

Since the inception of a non-racial, non-sexist democracy in South Africa in 1994, it is not surprising to find many mothers have entered various professional fields and occupations. "The influx of women into the workforce, the economic necessity of two-income families, the increase in single-parent families, child care and elder care availability and affordability, and increased time pressure have all contributed to work and family concerns" (Gebeke, 1993:1). Unfortunately many families and businesses have neglected to adapt to these changes. The women-in-business debate, however, has changed because so much has changed socially over the last 15 years (Bendeman, 2007). The increased pressure that employers place on employees to meet the needs of their customers and run a profitable business needs to be addressed, as employers, according to Blanchard (2000), need to put effective structures and systems in place for people to want to perform.

Daily strains, such as childcare breakdown or an emergency caused by illness, could lead to increased employee absence. Unscheduled leave or absenteeism may have an impact on the productivity of the working mother, as well as a financial impact on the bottom line of almost any company (Smanjak, 2007). From a business point of view, the important outcome is productivity and bottom-line income. The focus is moving from "How many hours do you spend at work?" to "What did you do during that time?" If family and work-life involvement are managed efficiently, the possibility is that this can have a positive effect on the systems.

Ferreira (2000) believes that South African firms, given the unique circumstances and competitive position on the African continent, have plenty of opportunities to become real pathbreakers. The author continues that "path breaking is a lot more rewarding than benchmarking" (Ferreira, 2000:7). It is thus essential to determine how family dynamics influence the productivity of the working mother.

\section{SYSTEMS AS PART OF LIFE}

Ambrosino, Heffernan, Shuttlesworth and Ambrosino (2005:447) state that "the increase in the number of women employed outside the family has been fairly sudden, leaving both employers and families unprepared to deal adequately with the resulting implications". The permanent attachment of women to the world of work reminded industry of what social workers already know: "that work and family are not separate worlds and what occurs in one inevitably affects what happens in the other" (Kurzman, 2008:314). This means that mothers are part of different systems that shape their lives and the lives of their families.

Within these systems mothers have different roles that are unique to the specific system and complementary to one another. The mother now functions within two main systems: the economic system, which includes the mother in the workplace and the social system, which entails the family. Interaction within one system might influence the dynamics in other systems that the individual is involved in because, according to Ambrosino et al. (2005), it is impossible to keep the two systems separate. The economic system refers to the mother being part of the labour market, which implies that she has had to learn to balance both the family system and 
the work environment. The social system refers to the family, which is outlined by concrete or abstract boundaries in the form of family rules and behaviour. Hlapolosa (2000) states that the emerging worker demands a balance between career and family, while pursuing organisational goals.

Research done by Katz (2003) shows that the success of businesswomen is not derived so much from what they are doing, as it is from the support structures on which they rely. Mutual social support and empathy with others in women's lives are important. Simpson and Haselau (2006:284) indicate that "empathy, together with unconditional positive regard and genuineness are sufficient qualities for effective helping".

Prokopenko (1992) indicates that people are the most important aspect of productivity and the standard of living of many individuals can be increased directly by improving the level of productivity. That is why Heap (1992:4) says that "changes in productivity levels may have a major influence on many social and economic issues such as economic growth, higher standard of living, inflation control and even the quality of leisure and the amount thereof'. Each individual evaluates his/her productivity according to his/her own measurements. The key to productivity can thus be seen as the attitude of people who work together. This is also in a way related to commitment, or the lack thereof. It can therefore be stated that attitude leads to commitment, and positive communication leads to productivity. This attitude can be influenced by the system in which an individual functions. The working mother's own attitude, motivation, knowledge and skills can thus determine the influence she has on her own productivity and behaviour within the workplace.

\section{INNER CONFLICT IN THE WORK SITUATION}

The working mother has certain roles to fulfil. Some of the roles might be contradictory or even overlap. This unfortunately causes role conflict between work and family life. Cooper and Lewis (1998) describe how the inner conflict within a working mother can lead to lack of productivity at work. Research done by Campbell (1994:1) shows that "women with children were significantly lower in occupational commitment relative to women without children". Wentling (1998:16) elaborates on this by stating that conflict between work and family will "increase the possibility that employees will work less efficiently". The author also mentions concepts such as family structure, relationships and the support services available that will have some influence on work and family conflict. It seems thus that conflicting roles and the strain that this causes is one of the important aspects to consider when analysing work-family relations. This could suggest even further that single parents experience the stress and influence of family dynamics more intensely than married couples, who have the support structure of a partner.

Legislation such as the Employment Equity Act in South Africa (Act 55 of 1998) can bring about changes in the demographics of a company. This necessitates a change in the way of thinking by top management, because Coontz and Parson (1997:448) indicate that difficulties mothers face in balancing productivity at work and family life "originate in contradictions within business and government policies, not within motherhood itself". In order to do so management needs to be made aware of the changing needs of their employees and especially of the working mother. Bendeman (2007:36) suggests that "careful attention to integration of concerns into mainstreamed policies and strategies should become a consistent commitment". 


\section{RESEARCH METHODOLOGY}

The study was undertaken at a leading company in the motor industry in Gauteng, South Africa. The main focus of business is importing, manufacturing and marketing of motor vehicles. This company is the base which is responsible for all auxiliary services such as human resources, finance, employee wellness and the payroll. Of the 192 employees, 123 are women. This means that $64 \%$ of the company's workforce are women. The population relevant to this study included all working mothers within this company in Gauteng. According to the Human Resources Department, of the 123 female employees, at least $90 \%$ are mothers. The population thus consisted of 111 working mothers.

Systematic sampling was used as a method of sampling, where respondents were selected according to particular intervals (Strydom \& Venter, 2002). In the study 28 working mothers who are employees of the specific company were invited to participate in three group sessions with the focus on the influence of family dynamics on the productivity of working mothers. The aim was to gain an insight into, and understanding of, the day-to-day lives of the working mother. The respondents were aged between 30 and 50 years. The respondents' children were between the ages of five and 18 years.

The following themes and sub-themes were extracted from the data collected in the study.

\begin{tabular}{|l|l|}
\hline \multicolumn{1}{|c|}{ THEMES } & \multicolumn{1}{c|}{ SUB-THEMES } \\
\hline Reasons for pursuing paid work outside the home & $\begin{array}{l}\text { Financial } \\
\text { Socialisation } \\
\text { Recognition } \\
\text { Technological development }\end{array}$ \\
\hline Issues of the working mother related to day-to-day living & $\begin{array}{l}\text { Illness of children } \\
\text { After-school activities } \\
\text { Role conflict }\end{array}$ \\
\hline Emotions experienced by the working mother & $\begin{array}{l}\text { Guilt } \\
\text { Dissatisfaction } \\
\text { Frustration }\end{array}$ \\
\hline Support structures of the working mother & $\begin{array}{l}\text { Partners } \\
\text { Family of origin } \\
\text { Friends }\end{array}$ \\
\hline Work environment & $\begin{array}{l}\text { Success and productivity } \\
\text { Balance }\end{array}$ \\
\hline
\end{tabular}

\section{THEME 1: REASONS FOR PURSUING PAID WORK OUTSIDE THE HOME}

\section{Financial}

The responses presented a clear picture of the most important reasons for women pursuing paid work outside the home.

After my divorce I had to work to find my feet.

After divorce, financial independence is important.

No money, no fun.

I work for a better lifestyle. 
Placing children in private schools where they have access to the best possible opportunities can be an expensive exercise for which an extra income is needed.

These statements confirm the literature that says financial independence is necessary in order to provide for the basic needs of people (Hodgetts, 1992). According to Hodgetts, a second income provides for safety and leisure-needs and can therefore contribute to a higher standard of living. Paid work outside the home seems to be the only option, as most of the respondents work because of financial pressure. It is also a fact, however, that financial independence entails more than just survival and meeting basic needs. Maintaining a high standard of living and providing for children's needs such as schooling and after-school activities are good enough reasons for the respondents to be working outside the home. It seems from these data that mothers not only work for an income in order to provide for basic needs of the family, but also to maintain a high standard of living.

\section{Socialisation}

Because time is in such short supply, friendships are difficult to maintain. The following statements indicated the responses:

Sometimes the only interaction and friendships that I have are those within the work environment.

Interaction that one has with people at work and dealing with certain situations keeps the mind stimulated.

I work in order to protect my sanity.

I enjoy working because I like the interaction.

This is confirmation that socialisation with others is extremely important for individual growth and success (Hodgetts, 1992), yet according to Erdwins, Buffardi, Casper and O'Brien (2001), it is difficult to maintain.

\section{Recognition}

The following statements indicated the responses on recognition.

I want to work because I want a career.

I will work irrespective of the financial situation, and do what I want to do after working hours.

According to Kasselman (2000), recognition will lead to a well-defined self-esteem. Ritchie and Martin (1999) identify recognition as one of the twelve factors that, according to them, motivates people to work. These excerpts reiterate the views of Ambrosino et al. (2005) that individuals today expect more from the workplace than just a pay cheque. Bendeman (2007:35) takes this further by stating that "not only do women in South Africa now have a constitution protecting their rights and freedoms, but there is a myriad of laws and legislation protecting their interests", which is supposed to make it so much easier for the working mother to fulfil the need for recognition.

\section{Technological development}

The following statements confirmed that respondents want to remain abreast of developments in their work.

Technology is developing at an enormous rate. 
In order to keep up with technological advances, women need to stay in the labour market.

Even in the short period of time during which one does not work, things will change and it will take time to gain confidence, for instance, in new computer systems.

By learning new things, one feels more fulfilled (Hodgetts, 1992). The author continues that technology is developing at an enormous rate and keeping in touch goes hand in hand with stimulating the mind. All the above-mentioned motivations for taking paid work outside the home makes the mother independent, not only financially independent, but emotionally and socially as well. According to the researchers, providing for financial needs, social needs, selfactualisation and recognition will lead to independence.

\section{THEME 2: ISSUES OF THE WORKING MOTHER RELATED TO DAY-TO-DAY LIVING}

Respondents feel that there are so many roles within the home as well as the work environment that it becomes confusing and tiring to cope. Yet mothers are expected to excel in all the different roles. This can cause them to "snap" at some point or another.

\section{Illness of children}

The first issue that mothers often have to deal with is the illness of their children. The following statements confirm the difficulties that the respondents have to deal with:

I once cancelled an important business trip in order to stay with my sick child.

As a single mother I feel no one else is capable of caring for my child during illness.

If my child is ill and I have an important meeting at work, I have to decide which I should

do first, take her to the doctor or attend the meeting; I constantly feel torn in two directions.

According to Michaels and McCarty (1993), mothers are typically the ones to take care of a sick child. Whether it is herself, a child or another family member who is ill, arrangements are often necessary to ensure proper care and recovery. When children are still very small, they need to be comforted and cared for by the mother herself, which is not always possible because of the work environment. It is unthinkable for Bendeman (2007) that 15 years after democracy women still need to spend hours on the debate around childcare facilities or breastfeeding, for that matter. Yet statistics from the $\mathrm{CCH} 2006$ survey done on absenteeism indicate that personal illness accounts for only $35 \%$ of unscheduled absences, while $65 \%$ of absences are due to other reasons including family issues (24\%) (Smanjak, 2007).

\section{After-school activities}

Transport arrangements and safety seem to be an issue for some mothers. The security of the children while travelling from home to school and back seems to present the greatest difficulty. According to Jex (1999), this can jeopardise the feeling of self-actualisation and productivity. Working parents who are concerned about what their children are doing after school are less engaged in their jobs than they could be, and are costing their employers in terms of lost productivity (News Briefs, 2007). This was confirmed by the following responses:

My children rely on public transport and phone me just after two to say that the bus never came. For me it's a two-hour drive to pick them up and take them home. The children have no choice but to wait until four o'clock when I can pick them up.

I am always worrying about them and making phone calls to ensure their safety. 
Because of pressurised lives and working outside the home, the children become more independent.

They need to fight for themselves and I am not always sure what they are up to.

This once again confirms Maslow's hierarchy of needs, in that the safety of one's children comes before one's own needs to build self-esteem and receive recognition (Hodgetts, 1992). Worries about children's after-school activities diminish the productivity of working parents. Levels of parental concern about after-school time (PCAST) are the highest amongst single parents (News Briefs, 2007). In other words, the responsibility still stays with the primary caregiver of the home, the mother. According to the researchers, the mother also has a responsibility towards the children in the fulfilment of their needs, as indicated by Maslow, on all different levels.

\section{PARENTAL CONCERN ABOUT AFTER-SCHOOL TIME}

\section{Role conflict}

Respondents identified role conflicts with the following responses:

There are so many roles within the home as well as the work environment that it becomes confusing and tiring to cope.

It is expected of mothers to excel in all the different roles. This can cause one to "snap" at some point or another.

When leaving the work environment we are entering our second job with its own unique roles and challenges.

I organise everything from the menu to the dentist appointments before leaving on a business trip.

Nordenmark (2002) indicates that the combination of family and employment demands creates more demands than one can handle. This increases the risk of conflict between paid work outside and the role at home. In the light of this role conflict, the mother is unable to attend fully to the personal demands because of the work environment. In turn, the work environment could be temporarily neglected to allow time for the mother to refocus her attention. Vosloo (1999) stresses that maintaining the balance between work and family life causes role conflict within the working mother.

\section{THEME 3: EMOTIONS EXPERIENCED BY THE WORKING MOTHER}

Thompson (2005) indicates that work-family conflict is often associated with job and life dissatisfaction, depression, anxiety, anger/hostility and perceptions of a lower quality of life. Respondents identified emotions experienced with the responses described below.

\section{Guilt}

Cooper and Lewis (1998) indicate that mothers feel guilty about leaving their children, especially in a time of crisis, for example, illness or during the school holidays. The following statements illustrate the responses:

When you have an emergency over month-end, it feels like you're going to let someone down. I would rather let the children down than the company.

I experienced an atmosphere of blame for not being emotionally accessible. 
A mother's first priority lies with her children and yet in order to provide a better lifestyle for them, I need to work and earn a salary. Feeling guilty therefore goes both ways and is inevitable.

This situation causes mothers to feel guilty towards their children for not attending to them and guilty towards the company for spending company time to deal with a home crisis. Elman (2003:1) states:

"We are passionate about our careers, and that's a good thing - we have every right to be! Yet it can be so difficult to focus on work without constantly worrying about how our children are getting along without us, and that never changes, no matter how old they get."

It is thus often a conflicting struggle to balance the responsibilities of motherhood and the workplace. Hosking (2007:55) warns that if parents are not careful, they can very easily allow work-related thoughts to block out the messages they need to hear from their children. Although guilt is one of the most powerful emotions experienced by the working mother in these situations, it is important to remember not to measure oneself according to the standards set by stay-at-home mothers (Cooper \& Lewis, 1998). There should, according to the researchers, be a distinct differentiation.

\section{Dissatisfaction}

The following statements indicate a feeling of dissatisfaction:

Sometimes you are so drained, but you have to go on.

When one has the time to evaluate life in all its facets, it seems that I'm not a happy person any more.

I am dissatisfied with life, but because I cannot afford to be distracted, I resume my responsibilities.

Don't rock the boat, it affects your bonus.

It seems that this feeling of dissatisfaction is temporary and is the mothers able to still survive. In this instance dissatisfaction could be closely related to role conflict. In other words, role conflict could lead to dissatisfaction. It could also indicate inadequate job satisfaction (Cooper \& Lewis, 1998; Erdwins et al., 2001). Bendeman (2007) indicates that women need to be taken from their own point of survival to their own defined point of excellence. Through this process they can get rid of the feeling of dissatisfaction.

\section{Frustration}

According to most companies' policies, children are not allowed on the premises and, therefore, family situations must be attended to off-site. Although managers often comprehend and empathise with the working mother and her unique situation, they also need to ensure the productivity of the company. Therefore they cannot always grant the necessary time off. It is expected of the working mother to understand this, yet it contributes to the levels of frustration. This was confirmed by the responses set out below:

Dealing with a crisis at home is very tiring and emotionally distressing.

One cannot leave the office at the drop of a hat and that leads to a feeling of panic.

When a crisis occurs, especially over month-end, I experience a high level of frustration.

I cannot focus on what I am busy with while being concerned about a crisis situation at home. This lack of concentration intensifies my level of frustration. 
This confirms what Cooper and Lewis (1998) indicated, namely that no matter how well organised childcare and backup systems are, there is no guarantee that nothing will go wrong. This links with the findings concerning role conflict; these issues do not seem to leave very much time for oneself. It is therefore understandable that some mothers and children cannot cope with everyday life.

\section{THEME 4: SUPPORT STRUCTURES OF THE WORKING MOTHER}

In dealing with a family crisis, most people rely on support from other people. Some of the respondents have a well-maintained support network, while others do not. The lack of a support system intensifies feelings of frustration (Cooper \& Lewis, 1998). Women in jobs that entail high work demands, low levels of job control and who have little workplace social support are more likely to suffer poor health and to have their health decline than are women who have more flexible jobs with reasonable demands and social support (Major study of women at work..., 2000). The respondents reacted as follows on availability of support and the implications of this.

\section{Partners}

Partners are the most important support structure for the working mother. The following responses were made.

I could never do my job the way I do now without my husband.

My husband helps with certain household chores and is emotionally supportive.

These statements confirmed that partners are the most important support structure for the working mother (Coontz \& Parson, 1997). The researchers are of the opinion that a partner might be more flexible in that he often travels during office hours and can therefore quickly attend to family matters, whilst women in this motor company are often office bound. Although this study did not focus on single parents, it seems clear that marital status and the support of a partner influence the functioning of the family and working mother.

\section{Family of origin}

Parents and family of origin fulfil certain needs within the system, which provides a support structure for the working mother and her family. The support experienced from the respondents' family of origin varied.

I am not married and my parents stay in another part of the country, therefore I do not have any kind of support.

My mother lives with us and therefore is available to assist with practical arrangements.

My family stays nearby and helps in time of a crisis.

My family serves as support as they experience similar kind of obstacles.

Parents and family of origin form part of the social system in which the working mother functions (Hunts \& Marotz-Baden, 2003). It is assumed that grandparents may not have the kind of time constraints that brothers or sisters with their own families have, and are thus more available to help in crisis situations than other family. The brothers and sisters, however, serve as support as they experience similar kind of obstacles. Grandparents fulfil certain needs within the system and this provides a support structure for the working mother and her family. 


\section{Friends}

Respondents felt that because of long working hours and family demands it is difficult to maintain existing friendships and establish new ones.

I do not have any kind of support structure.

Even when time is available to invest in friendships, the family sometimes feels neglected and jealous of time spent away from them.

I do not have any support structure and dealing with a crisis is therefore very tiring and emotionally distressing.

This poses a challenge when no other support is available (Cooper \& Lewis, 1998). It is also important to remember that friends have families with dynamics of their own, work demands and support structures to maintain, and do not always have the time and energy to attend to the needs of others. The researchers, however, found it interesting that during the study not one of the respondents mentioned any emotions concerning time spent with the extended family or other friends as an issue in their day-to-day living. This might limit their support structures and cause their situation to deteriorate over time.

\section{THEME 5: WORK ENVIRONMENT}

\section{Success and productivity}

The respondents described productivity in terms of the success of their family, children and work life.

My children's success is an indication of my own success as a mother.

The high workload does not allow time to structure the work according to one's own measures.

I do not have time to do filing and organising my personal working space.

When personal issues arise, I do not have a choice but to concentrate and focus on my part of the job, otherwise the deadline will not be met.

The work must be done, even if it is completed after hours.

It takes a while to get back on track with one's work in case of an emergency at home.

The children's successes serve as a measure of a mother's success. However, children's success does not imply the mothers' success as an employee. Du Brin (1996:306) defines productivity as "the amount of quality work accomplished in relation to the resources consumed". As a working mother and employee of this motor company, the measurement structures are already in place within the company. These include bonus structures, set goals and deadlines that have to be met. It can thus be stated that if the mother as an employee achieves her goals and meet the deadlines, she experiences herself as being successful, which implies productivity.

\section{Balance}

For an individual to experience optimal functioning, a balance between work, leisure and family time is of the utmost importance. According to the respondents, balance is something that does not happen by itself, but is created by the individual.

We create our own balance, because we have no choice.

We establish our own boundaries and, if we have support, it is easier to maintain a balance.

One needs to learn not to take work problems home and home problems to work. 
One has to be at peace with oneself.

Hlapolosa (2000) states that the emerging worker demands a balance between career and family while pursuing organisational goals. It seems thus that the working mother has a responsibility towards her family and herself to be in control and balance her two worlds.

\section{CONCLUSIONS}

The women in this study combine childrearing responsibilities with paid work. While some mothers argue that both they and the children benefit from their workforce participation, it is still difficult to make choices in the best interest of their children. The material gains from working are important to many mothers as well as the wish for self-fulfilment, although it seems women's work and family choices are not wholly self-sacrificing or wholly selfinterested.

Working mothers experienced socialisation with others to lead to individual growth and success, especially when it is combined with work, which will contribute to the development of a well-defined self-esteem. If employment outside the home enhances the mother's sense of competence, achievement and self-worth, it is likely to spill over to other areas of her life activity.

Less visible are the emotional costs when mothers go to work. Day-to-day issues that the working mother needs to deal with lead to feelings of guilt that come from actions or omissions. This experience of guilt arises from the gap between the guilt-triggering action or non-action, and the guilt feeling itself towards the children or the employer.

As spending time with the extended family or other friends was not mentioned as an issue in the working mother's day-to-day living, this might indicate that their support structures are limited and this in turn results in their situations deteriorating over time. The availability of a support structure however, could minimise the effect of work-family conflict on the productivity of the working mother.

It seems that the working mothers struggle to survive the challenge of balancing both the family system and the work environment. There seems to be a discrepancy between thinking of themselves and setting the needs of others first. The company may also be able to relieve some of the pressures experienced by the working mother by reconsidering some of its working practices.

\section{RECOMMENDATIONS}

Although policy is implemented to ensure productivity in this motor company in South Africa, it is implied that, in order for the company to be productive, the employee needs to work in an environment where productivity is promoted. The productivity of the working mother however, is influenced by work-family interaction and, therefore, it is suggested that the company should offer a family-friendly policy, including flexible work arrangements whereby the negative impact of work-family dynamics can be minimised. This necessitates a change in the way of thinking by top management, because the difficulties that mothers face in balancing productivity at work and family life originate in contradictions within policies and not within motherhood itself. In order to do this, management need to be made aware of the changing needs of their employees and especially of the working mother. Careful attention to integration of concerns into mainstreamed policies and strategies should therefore become a consistent commitment. 
In view of existing role-conflict and the potential decline of productivity, it is suggested that infrastructure be developed at work to assist working mothers in managing their roles. Some simple work-scheduling changes could significantly improve the wellbeing of the working mother and would have minimal impact on the company.

Mothers also need to understand that effective time management and the utilisation of support structures could minimise the effect of role conflict within systems. A specific development intervention should be designed to teach working mothers that they are ultimately the designers of their own privileged circumstances or misfortune in the company. Mothers should thus become involved in the design and implementation of change in their work environment. The working mother needs to be trained in addressing the relationship between experiencing guilt and her ideas about who she is and who she wants to be. The conflict thus needs to be addressed between the mother's action/non-action and her idea of who she actually is or wants to be, or how she would want to act.

The company must become the employer of choice. It must become the greatest place to work for, so the employer needs to focus on its people as the most important aspect of productivity. The structures and systems in the company need to enhance the working mother's ability to perform. As the majority of the company's employees are women (64\%), of which $90 \%$ are mothers, the development of the ability to spot opportunities in the company needs to be enhanced. The focus needs to be on getting working mothers from the level of "survival" to "excellence". These concepts need to be defined for each individual by the women themselves - within the context of the company's strategic focus.

\section{REFERENCES}

AMBROSINO, R., HEFFERNAN, J., SHUTTLESWORTH, G. \& AMBROSINO, R. 2005. Social work and social welfare an introduction $\left(5^{\text {th }} \mathrm{ed}\right)$. Australia: Thomson, Brooks/Cole.

BENDEMAN, H. 2007. Beating the drums on the gender bandwagon. HR Future, Human Strategy for Business, 07:34-36.

BLANCHARD, K. 2000. Talent and passion. Teaming up for the year 2000. Management Today, 16(1):10-13.

CAMPBELL, D.J. 1994. The effects of family responsibilities on the work commitment and job performance of women. Journal of Occupational and Organisational Psychology, 67(4):1-15.

COONTZ, S. \& PARSON, M. 1997. Complicating the contested terrain of work/family intersections. Journal of Women in Culture and Society, 22(2):440-452.

COOPER, C.L. \& LEWIS, S. 1998. Balancing your career, family and life. London: Kogan Page.

DU BRIN, A.J. 1996. Human relations for career and personal success. New Jersey: Prentice Hall.

ELMAN, C.B. 2003. Juggling career and kids. Women in Business, 55(3):3.

EMPLOYMENT EQUITY ACT, 1988 (Act 55 of 1998). Government Gazette, No. 19370. Pretoria: Government Printers. 
ERDWINS, C.J., BUFFARDI, L.C., CASPER, W.J. \& O'BRIEN, A.S. 2001. The relationship of women's role strain to social support, role satisfaction and self-efficiency. Family Relations, 50:230-238.

FERREIRA, A. 2000. A new competitive landscape. Strategic challenges for the $21^{\text {st }}$ century. Management Today, 16(1):4-7.

GEBEKE, D. 1993. Family-supportive workplace environments: the employer's role. NDSU Extension Service. Available: http://www.extnodak.edu [Accessed: 15/10/2003].

HEAP, J. 1992. Productivity management. New York: Cassell Educational Ltd.

HLAPOLOSA, S. 2000. Organisation development. Management Today, 16(1):14-21.

HODGETTS, R.M. 1992. Modern human relations at work. Orlando: The Dryden Press.

HOSKING, A. 2007. Listen to your children. HR Future, Human Strategy for Business, 07:55-56.

HUNTS, H. \& MAROTZ-BADEN, R. 2003. Family systems theory: a new look at an old friend. Consumer Interests Annual, 49(3).

JEX, S.M. 1999. Time management as a moderator of relations between stressors and employee strain. Work and Stress, 13(2):182-191.

KASSELMAN, J.P.H. 2000. Loopbaanontwikkeling in verhouding tot bedryfsmaatskaplikewerk: ' $n$ teoretiese fundering. [S.n.]

KATZ, M. 2003. The business mother in today's workplace. Women in Business, 55(3).

KURZMAN, P.A. 2008. Occupational social work. The Encyclopedia of Social Work, 20(3):311-319.

MAJOR STUDY OF WOMEN AT WORK LINKS JOB STRESS WITH POOR, FAILING HEALTH. 2000. New Therapist, July/August:7.

MICHAELS, B. \& McCARTY, E. 1993. Family ties and bottom lines. Training and Development, March:70-73.

NEWS BRIEFS. 2007. Worries about children's after-school activities lower productivity of working parents. Journal of Employee Assistance, 37(2):30.

NORDENMARK, M. 2002. Multiple social roles - a resource or a burden: Is it possible for men and women to combine paid work with family life in a satisfactory way? Gender, Work and Organisation, 9(2):125-145.

PROKOPENKO, J. 1992. Productivity management. Geneva: International Labour Office.

RITCHIE, S. \& MARTIN, P. 1999. Motivation management. Brookfield, USA: Gower.

SIMPSON, B. \& HASELAU, C. 2006. Empathy in the South African context: relevant or redundant? The Social Work Practitioner-Researcher, 18(3):283-297.

SMANJAK, P. 2007. Four steps to reduce cost of absence. HR Future, Human Strategy for Business, 07:21-22.

STRYDOM, H. \& VENTER, L. 2002. Sampling and sampling methods. In: DE VOS, A.S. (ed), STRYDOM, H., FOUCHÉ, C.B. \& DELPORT, C.S.L. Research at grass roots: for the social sciences and human services professions $\left(2^{\text {nd }} \mathrm{ed}\right)$. Pretoria: Van Schaik Publishers. 
THOMPSON, C.A. 2005. Work-life: organisations in denial. Journal of Employee Assistance, 35(2):7-9.

VOSLOO, S.E. 1999. Rolkonflik by die werkende moeder - 'n geestesgesondheidsperspektief. Pretoria: University of South Africa. (Unpublished DComm Thesis)

WENTLING, R.M. 1998. Work and family issues: their impact on women's career development. New Directions for Adult and Continuing Education, 80:15-23.

Ms Liesl Riekert, postgraduate student, Dr Florinda Taute, Department of Social Work and Criminology, University of Pretoria, Pretoria, South Africa. 